\section{Why the Pacific status quo is no longer an option}

FATHER FRANCIS X. HEZEL is a GUam commentator and blogger on Pacific issues. He was the founder and long-time director of the Micronesian Seminar in Pohnpei.

Idyllic No More: Pacific Island Climate, Corruption and Development Dilemmas, by Giff Johnson. Majuro, Marshall Islands: CreateSpace. 2015. 153 pp. ISBN 978-1-512235-58-6

IFF Johnson's latest work, Idyllic No More: Pacific Islands Climate, Corruption and Development Dilemmas, is a call to serious planning and more. The Marshall Islands Journal editor summons leaders to recognise that life has changed in the country and the status quo is the road to disaster.

There was a time when this might not have been true - when people who wanted to kick back and live a simple island life could quietly opt out of school and retire to the family land to provide for themselves as their ancestors had done for generations in an island society that offered the resources, physical and social, to support its population.

But times have changed, the author convincingly argues through this collection of essays, drawn largely from his blog at the Vanuatu-based Pacific Institute of Public Policy. That kind of idyllic fallback is no longer an option. Residents of the Marshall

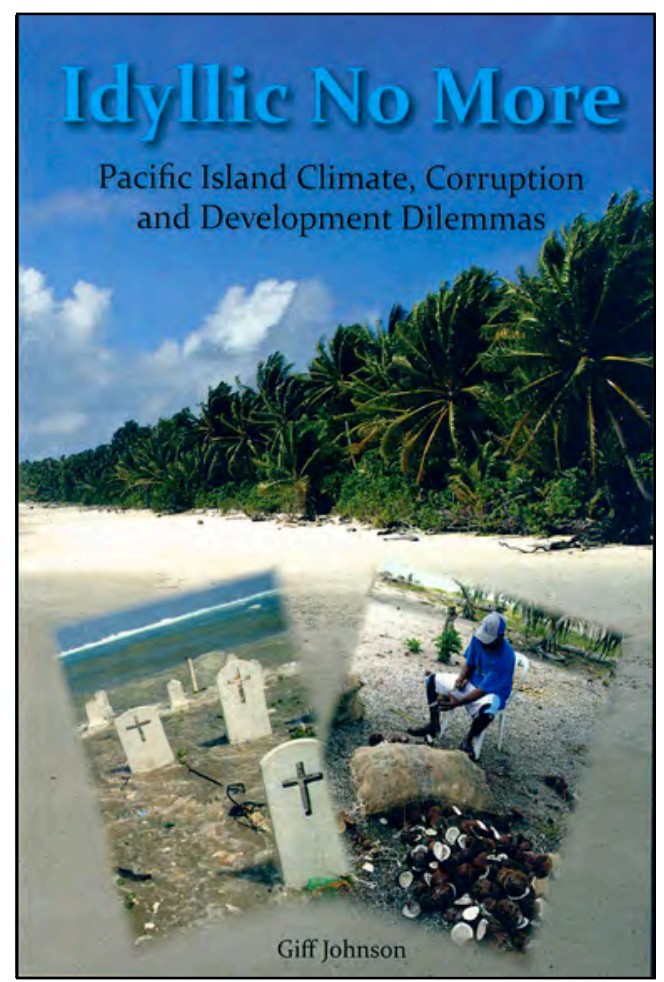

Islands, including those outer atolls where life was simple and cheap, are voting with their feet.

The outflow of Marshallese to the United States is steadily increasing, slowly emptying the remote atolls even as it drains the population of the two large population centres, Majuro and Ebeye. Islanders today expect meaningful employment but find none at home.

Marshallese today want more but seem to be getting less. Water supplies are contaminated in many places, the copra industry which once provided modest disposable income for those who worked the land has gone south, and the quality of education is not what it once was.

No wonder people now describe them- 
selves as 'poor'. Normal household tasks have become more challenging with the breakdown of the old extended family on which they relied. As a result, even basic care of children often leaves a lot to be desired.

In today's world no island is simply an island. All nations have subscribed, willingly or not, to standards that are spelled out in global millennium development goals (MDGs).

Measured by these standards, progress in the Marshalls has stalled.

Donors may open their hearts and wallets to the Marshalls, but the money given is all too often regarded as a treat to be passed around the table and sampled by everyone rather than for its real purpose. Consultants come in and craft a report outlining reform measures that goes unread and unimplemented.

Government employees fly off to attend meetings that multiply each year and leave them little time to provide the public services their people so badly need.
How does this small island nation chart a new course for itself? One that offers it the hope of finding new resources while conserving those it now has? One that provides a pathway to the development that government and people claim to want for themselves? One that is, in that overworked phrase, sustainable?

The answer is not nearly as elusive as it might appear, the author suggests. But making this happen will require reform: a change in habits, especially on the part of the government, and a readiness to implement practices that we know can be successful but threaten our own interests.

That's what it will take, no matter whether we're dealing with global warming, preserving fish stock in national waters, improving education and health services, or trying to make the heavy emigration work to the advantage of the Pacific.

\section{Reference}

Giff Johnson's PiPP blog: pacificpolicy.org/ author/gjohnson/ 